\title{
Detection and molecular characterization of equine herpesviruses 1, 2, and 5 in horses in the Republic of Serbia
}

\author{
Andrea Radalj ${ }^{1}$, Jakov Nišavić ${ }^{1}$, Dejan Krnjaić ${ }^{1}$, Miroslav Valčić ${ }^{2}$, Tanja Jovanović3 \\ Ljubiša Veljovićc ${ }^{4}$, Nenad Milić ${ }^{1}$
}

${ }^{1}$ University of Belgrade, Faculty of Veterinary Medicine, Department of Microbiology, Belgrade, Serbia

${ }^{2}$ University of Belgrade, Faculty of Veterinary Medicine, Department of Infectious Diseases of Animals and Diseases of Bees, Belgrade, Serbia

${ }^{3}$ University of Belgrade, Faculty of Medicine, Institute of Microbiology and Immunology, Virology Department, Belgrade, Serbia

${ }^{4}$ Scientific Veterinary Institute of Serbia, Belgrade, Serbia

Received August 27, 2017

Accepted April 3, 2018

\begin{abstract}
The presence of equine herpesviruses 1, 2 and 5 (EHV-1, EHV-2 and EHV-5) was examined in 66 samples of spinal cord, submandibular lymph nodes and spleen of healthy, non-vaccinated abattoir horses from different locations in the Republic of Serbia. Virus isolation was conducted on RK-13 cell line with the confirmation of isolated viral strains by multiplex nested polymerase chain reaction. The cytopathic effect was observed $48-72 \mathrm{~h}$ after the first inoculation in 28 $(42.4 \%)$ organ samples, and after 5 days in 11 other samples $(16.7 \%)$ that were all confirmed as EHV-1. Four other samples $(6.1 \%)$ that showed cytopathic effects on day 5 of the third passage were all positive for EHV-5. Additionally, EHV-1, EHV-2, and EHV-5 were directly detected in all organs by multiplex nested PCR in $46(69.7 \%), 3(4.5 \%)$, and $7(10.6 \%)$ samples, respectively. The molecular characterization based on nucleotide sequencing of the part of the $\mathrm{gB}$ gene showed that Serbian EHV-1 isolates were 100\% homogenous and clustered with EHV-1 strains from Turkey, the United Kingdom, the United States, and Japan. The EHV-2 strain from Serbia branched together with Turkish EHV-2 isolates with homogeneity from $96 \%$ to $98 \%$. Serbian EHV-5 strains can be separated in one distinct cluster with isolates from Turkey and the United States with homogeneity from 98 to $99 \%$. These data represent the first report of the molecular characterization of EHV-1, EHV-2, and EHV-5 in the horse population of the Republic of Serbia and document the first successful isolation of Serbian EHV-5 strains.
\end{abstract}

\section{EHV-1, EHV-2, EHV-5, virus isolation, molecular characterization}

Equine herpesviruses are widely distributed around the world and cause diverse diseases in horses. Equine herpesvirus $1(\mathrm{EHV}-1)$ is classified as a member of the genus Varicellovirus in the subfamily Alphaherpesvirinae. Equine herpesvirus 2 (EHV-2) and equine herpesvirus 5 (EHV-5) that were historically called "equine cytomegaloviruses" belong to the genus Percavirus in the subfamily Gammaherpesvirinae (Davison et al. 2009). Equine herpesvirus 1 may cause latent infection in lymphoid tissue and the sensory and trigeminal ganglia, whilst stress, transport and intercurrent disease lead to virus reactivation in asymptomatic carrier horses with the spread of the disease in the equine population as a consequence (Edington et al. 1994; Pusterla et al. 2010; Negussie et al. 2017). Equine herpesvirus 1 causes respiratory disease in young animals, abortion in pregnant mares and neurological disease (Wang et al. 2007; Pusterla et al. 2010; Turan et al. 2012). The presence of EHV-1 in Serbia is known, however, there have been no recent reports of its potential connection to outbreaks of neurological disease or abortion in horses. Vaccination of horses against EHV-1 is not obligatory in Serbia and it is performed in accordance with the epizootiological situation in certain areas. Equine herpesvirus 2

Address for correspondence:

Andrea Radalj

Department of Microbiology

Faculty of Veterinary Medicine

University of Belgrade

Bulevar oslobodjenja 18, 11000 Belgrade, Serbia

Phone +381638884712

E-mail: andrea.zoric@vet.bg.ac.rs

http://actavet.vfu.cz/ 
causes immunosuppression, lymphadenopathy, upper respiratory disease, pharyngitis and pneumonia (Brault et al. 2011). Equine herpesvirus 5 is commonly found in nasal secretions and peripheral blood mononuclear cells of asymptomatic horses, nevertheless, not much is known about its potential role in infections associated with disease or poor performance in horses (Nordengrahn et al. 2002; Bell et al. 2006). A recent discovery connected progressive interstitial pulmonary fibrosis in horses termed equine multinodular pulmonary fibrosis (EMPF) and EHV-5 infection (Williams et al. 2007). The EHV-2 and EHV-5 are endemic in horse populations worldwide (Torfason et al. 2008; Ataseven et al. 2010; Negussie et al. 2017) although their presence has never been documented in Serbia. The mentioned herpesviruses have close antigenic similarities and often simultaneously infect the same horse (Nordengrahn et al. 2002; Torfason et al. 2008; Negussie et al. 2017). The polymerase chain reaction proved to be an asset for the laboratory diagnosis of viral infections and has also been applied in many studies of equine alpha and gammaherpesviruses (Nordengrahn et al. 2002; Wang et al. 2007; Torfason et al. 2008). Standard virological methods are more costly, laborious and time consuming compared to PCR; furthermore, the EHV-2 and EHV-5 slowly induce a cytopathic effect in cell culture and their isolation is not always successful (Wang et al. 2007; Williams et al. 2007; Diallo et al. 2008). The objective of this examination was to provide information on the detection of EHV-1, EHV-2 and EHV-5 in various organ samples from horses in Serbia and to perform the phylogenetic analysis of the Serbian EHV-1, EHV-2, and EHV-5 strains. Moreover, this study aimed to verify the application of multiplex nested PCR for a rapid and reliable detection of equine herpesvirus infections.

\section{Samples}

\section{Materials and Methods}

A total of 66 samples of the spinal cord, submandibular lymph nodes and spleen were obtained from 20 non-vaccinated healthy abattoir Lipizzaner and domestic horses. Samples originated from adult animals of 1 to 8 years of age and two healthy 8 -month-old foals. All animals were from different areas of the Republic of Serbia, namely, the municipalities of Ruma, Indjija, and Negotin, and were selected between November 2015 and March 2016. Immediately after sampling, the specimens were immersed into $2 \mathrm{ml}$ of minimum essential medium (MEM, Capricorn Scientific, Germany) with 2\% foetal calf serum (FBS-12A, Capricorn Scientific, Germany) supplemented with antibiotics and chilled on ice during transport to the laboratory. In the laboratory, all organ samples were homogenized in phosphate buffered saline (PBS 7.2) and centrifuged for $10 \mathrm{~min}$ at $1,677 \times g$. The supernatants were sterilized using sterile $0.22 \mu \mathrm{m}$ Millex syringe filter units (Merck, USA) and frozen at $-20{ }^{\circ} \mathrm{C}$ pending testing, whilst the deoxyribonucleic acid (DNA) was extracted from the cell debris using GeneJET Genomic DNA Purification Kit (Thermo Scientific, USA) according to the manufacturer's instructions.

Isolation of viruses in cell culture

For virus isolation, Rabbit Kidney-13 Cell Line (RK-13, ATCC CCL-37, IZSBS, Brescia, Italy) was used. All samples were individually inoculated onto 24 -h old and $80 \%$ confluent monolayer of RK-13 cell line in 24-well microtitre plates. Each well, after the aspiration of growing media, was inoculated with $100 \mu$ of sample and incubated for $1 \mathrm{~h}$ at $37{ }^{\circ} \mathrm{C}$ in an atmosphere with $5 \% \mathrm{CO}$. After $1 \mathrm{~h}, 500 \mu \mathrm{l}$ of MEM (Capricorn Scientific, Germany) supplemented with $2 \%$ foetal calf serum (FBS-12A, Capricorn Scientific, Germany) was added. The plates were incubated in the above mentioned conditions and observed daily for the appearance of the cytopathic effect (CPE) of the virus. If CPE was not observed after 7 days, the plates with the inoculated cell cultures were frozen and thawed $\times 3$ and passaged for two more times at 7-day intervals. In cases where no CPE was visible after the third passage, the sample was considered negative. Uninoculated cell monolayers were used as cell controls (Plate III, Fig. 1A). If CPE appeared in the monolayer of RK-13 cells, virus for further testing was grown in Roux flasks and DNA was extracted from the cells when the monolayer was from $60 \%$ destroyed using GeneJET Genomic DNA Purification Kit (Thermo Scientific, USA) according to the manufacturer's instructions. The virus isolates were further identified by multiplex nested PCR (Wang et al. 2007). As the positive control, strain of EHV-1, titre $6.25 \log _{10} 50 \%$ Tissue Culture Infective Dose $\left(\mathrm{TCID}_{50}\right.$ ) was kindly provided by The Scientific Veterinary Institute of Serbia. Internal laboratory reference strains of EHV-2 and EHV-5, titre $3.3 \log _{10} \mathrm{TCID}_{50}$ and $3.9 \log _{10} \mathrm{TCID}_{50}$, respectively, previously confirmed by sequencing were used as positive controls.

Multiplex nested PCR detection

The first and second round primers (Metabion International, Germany) used for PCR amplification of conserved regions of glycoprotein B (gB) genes of EHV-1 (188 bp), EHV-2 (817 bp) and EHV-5 (410 bp) as well as the 
protocol for the first and second round of PCR were described by Wang et al. (2007). The final specific PCR products were visualized using $1.5 \%$ agarose gel electrophoresis.

EHV-1, EHV-2, and EHV-5 gB gene direct sequencing

The EHV-1 specific primers from the first round of PCR amplifying the fragment of $1180 \mathrm{bp}$ along with EHV-2-and EHV-5 second round PCR primers used for the amplification of $817 \mathrm{bp}$ and 410 bp products were used for sequence analysis. The samples were sent for sequencing to the Macrogen Europe Laboratory, Amsterdam, Netherlands. The obtained nucleotide sequences from both directions were assembled together to obtain consensus sequences, aligned and compared with documented virus sequences available in the GenBank database using BLAST software (http://www.ncbi.nlm.nih.gov/BLAST/). Evolutionary analyses were conducted with MEGA 7 software. The phylogenetic trees for EHV-1, EHV-2, and EHV-5 strains were constructed using Maximum Likelihood algorithm with 1000 bootstrap replicates. The evolutionary distance was computed using Maximum Composite Likelihood method.

\section{Results}

Virus isolation

The cytopathic effect was observed 48-72 h after the first inoculation into the RK-13 cell line for twenty eight out of 66 tested $(28 / 66 ; 42.4 \%)$ organ samples and after 5 days in 11 other samples $(11 / 66 ; 16.7 \%)$ (Plate III, Fig. 1B). All samples were passaged $\times 3$ at 7 -day intervals and four $(4 / 66 ; 6.1 \%)$ other samples showed the characteristic herpesviral CPE with the formation of syncytia on day 5 of the third passage, whilst $23(23 / 66 ; 34.8 \%)$ remained negative. Because it was not possible to distinguish the CPE of specific equine herpesviruses in cell culture, all isolates were further identified by multiplex nested PCR. The presence of EHV-1 DNA was confirmed in 39 (59.1\%) samples, whilst EHV-5 DNA was discovered in four samples (6.1\%). All of the EHV-5 positive samples showed the characteristic herpesviral cytopathic effect at the third passage (Plate III, Fig. 1C). Equine herpesviruses 1 and 5 were isolated from various organ samples (Table 1). One isolate of both EHV-1 and EHV-5 originated from the same 8-month-old foal, whilst only EHV-1 was isolated from all tissue samples from its dam (8 years of age). Moreover, the other EHV-5 strains included in this study originated from horses from up to 2 years of age. All the virus-positive animals had no clinical signs of disease at the time of slaughter, i.e. sampling.

Table 1. Comparison of the results of polymerase chain reaction (PCR) and isolation of equine herpesviruses 1,2 and 5 (EHV-1, EHV-2 and EHV-5) in different organ samples.

\begin{tabular}{lccccccc}
\hline \multirow{2}{*}{ Sample type } & $\begin{array}{c}\text { Total no. } \\
\text { of samples }\end{array}$ & \multicolumn{2}{c}{ Polymerase chain reaction (PCR) } & \multicolumn{3}{c}{ Virus isolation } \\
\cline { 3 - 8 } & EHV-1 & EHV-2 & EHV-5 & EHV-1 & EHV-2 & EHV-5 \\
\hline Spinal cord & 22 & 15 & 1 & 0 & 12 & 0 & 0 \\
SMLN $^{*}$ & 22 & 19 & 1 & 4 & 15 & 0 & 2 \\
Spleen & 22 & 12 & 1 & 3 & 12 & 0 & 2 \\
Total & 66 & 46 & 3 & 7 & 39 & 0 & 4 \\
\hline
\end{tabular}

*SMLN - submandibular lymph node

\section{Multiplex nested PCR}

In relation to virus isolation, PCR proved to be more sensitive and specific (Table 1), with the exception of one spinal cord sample that was PCR negative but after virus isolation and subsequent PCR confirmation proved to be positive for EHV-1 DNA. The presence of EHV-1 was detected in 46 (69.7\%) samples, whilst EHV-2 and EHV5 DNA was discovered in three (4.5\%) and seven (10.1\%) samples, respectively. Mixed infections were detected for EHV-1 and EHV-5 in two submandibular lymph node samples and one spleen sample, whilst EHV-1 and EHV-2 DNA was discovered in one spinal 
cord sample. Infection with all three viruses was confirmed in one submandibular lymph node and one spleen sample. The EHV-2 was present only as a mixed infection in organ samples of one horse. The EHV-5 DNA was detected individually in only one sample of the submandibular lymph node and spleen of a single horse.

EHV-1, EHV-2, and EHV-5 sequencing and phylogenetic analysis

The results of the phylogenetic analysis of partial $\mathrm{gB}$ gene nucleotide sequences of two selected Serbian EHV-1 isolates demonstrated that they were 100\% homogenous and clustered with EHV-1 strains from Turkey (TR01, TR02, TR03, TR-McIIA-12, TRMCA-11, TR-GEA-11), the United Kingdom, the United States (NY05) and Japan (01c1), whilst their homogeneity was $99 \%$. Furthermore, the homogeneity between gB gene sequences of EHV-1 strains isolated from other species (strains CP5 and Ro-1 originating from a zebra and antelope, respectively) and Serbian EHV-1 isolates was 97\% (Fig. 2). The phylogenetic analysis of partial EHV-2 gB gene nucleotide sequences showed that the EHV-2 detected in this study clusters with Turkish EHV-2 isolates (Fig. 3). Serbian EHV-2 strain branched together with Turkish EHV-2 isolates and their homogeneity was from 96 to $98 \%$. Moreover, the similarities found between Serbian EHV-2 strain and German (Ger-5 and Ger-7) and isolates from The United Kingdom (Eng-12 and Eng-13) were $96 \%$. The Serbian EHV-2 strain was only $92 \%$ and $89 \%$ similar to strains from the United Kingdom (Eng-3) and Hungary (Hun-1), respectively, and only 78\% to the Icelandic EHV-2 isolate (Swe-2). Regarding the differences that were found between Serbian EHV-5 strains, they could be separated in one distinct cluster with three different branches (Fig. 4). The partial gB gene nucleotide sequences of isolates SRBEHV5/2 and SRBEHV5/4 were 96\% homogenous, whilst the homogeneity between isolate SRBEHV5/2 and strain SRBEHV5/3 was $97 \%$. The strain SRBEHV5/1 was $97 \%$ similar to isolate SRBEHV5/2 and 99\% homogenous to both SRBEHV5/3 and isolate SRBEHV5/4. The isolate SRBEHV5/4 and the strain SRBEHV5/3 branched together and were 100\% homogenous. The phylogenetic study of partial gB gene sequences of Serbian EHV-5 isolates and strains demonstrated

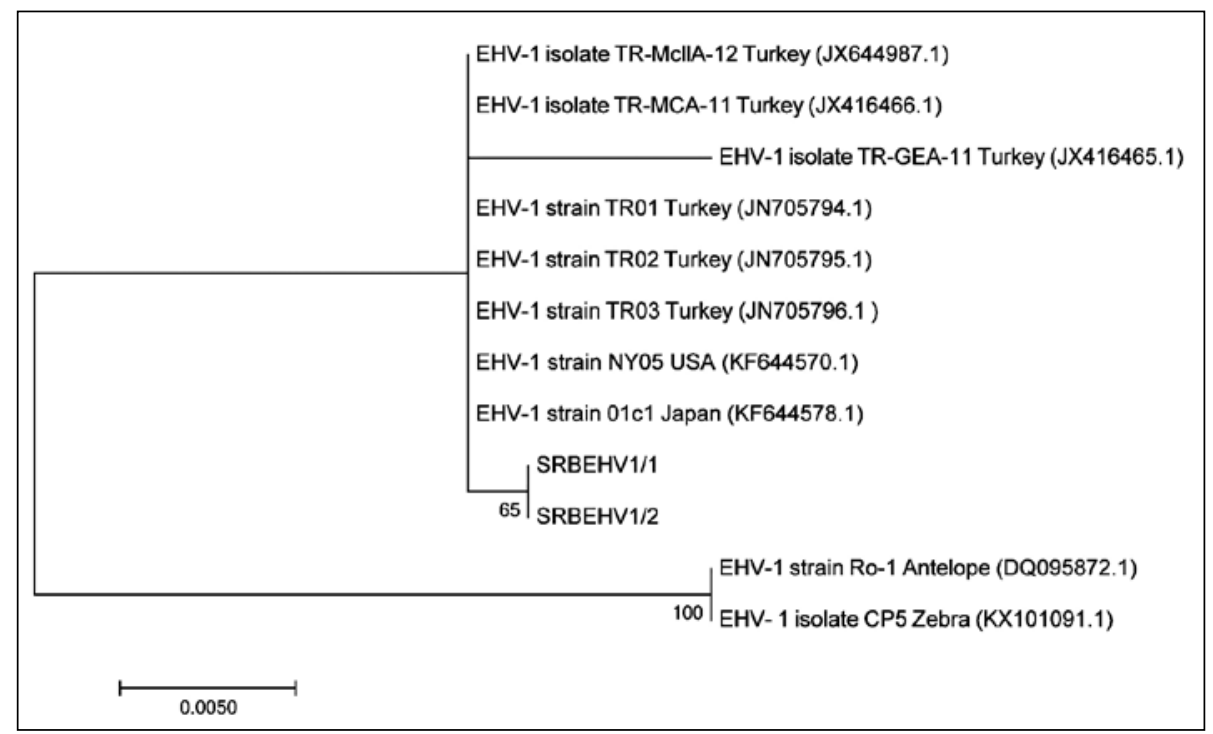

Fig. 2. Maximum Likelihood phylogenetic tree for gB genes of Serbian and foreign equine herpesvirus 1 (EHV-1) strains. Serbian EHV-1 strains are marked as SRBEHV1/1 and SRBEHV1/2. 


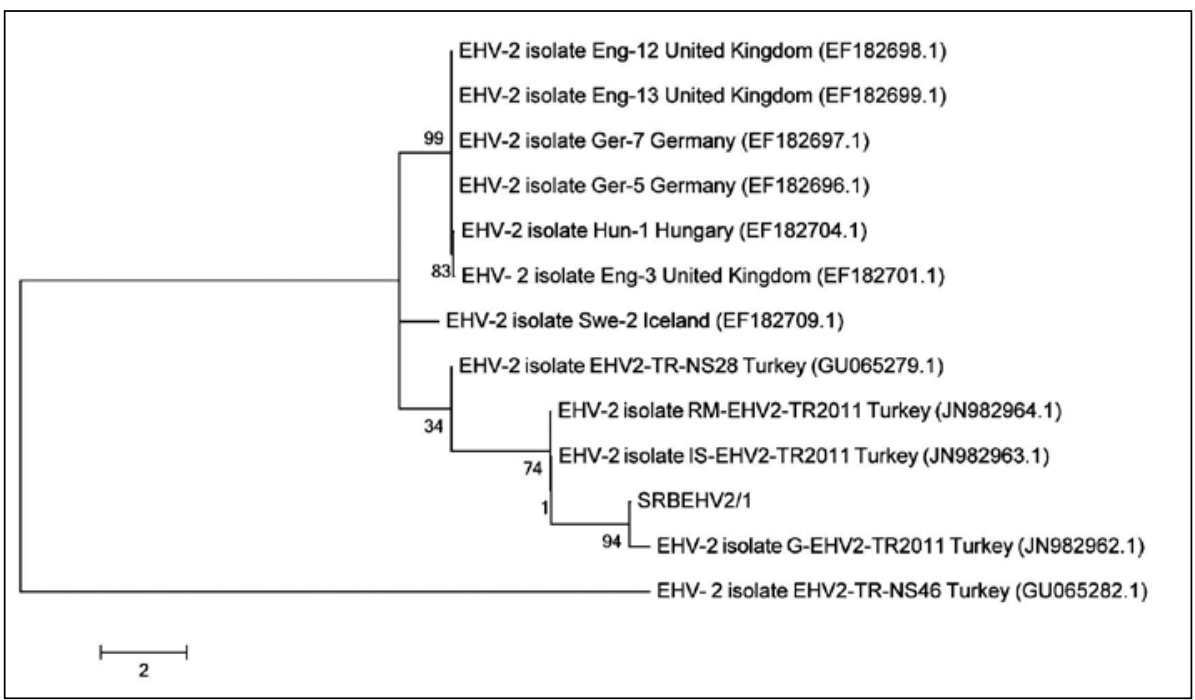

Fig. 3. Maximum Likelihood phylogenetic tree for gB genes of Serbian and foreign equine herpesvirus 2 (EHV-2) strains. Serbian EHV-2 strain is marked as SRBEHV2/1.

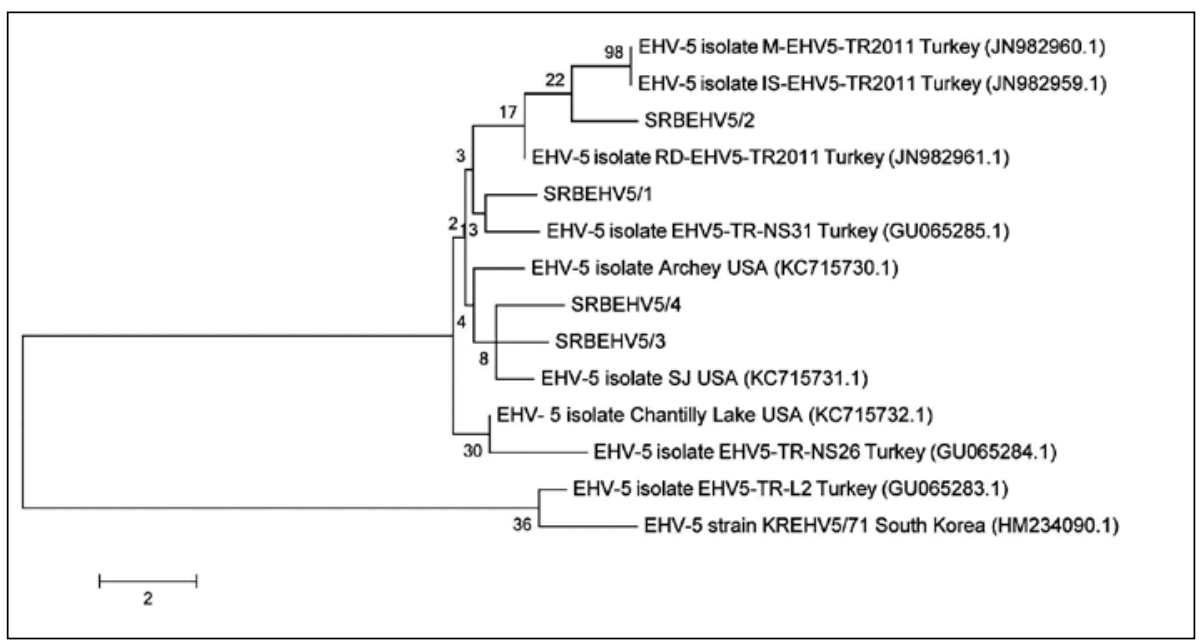

Fig. 4. Maximum Likelihood phylogenetic tree for gB genes of Serbian and foreign eqiune herpesvirus 5 (EHV-5) strains. Serbian EHV-5 strains are marked as: SRBEHV5/1, SRBEHV5/2, SRBEHV5/3, SRBEHV5/4.

significant similarities and clustering with isolates from Turkey and the United States. The similarities found between Serbian EHV-5 isolates and strains and Turkish EHV-5 isolates M-EHV5-TR2011, IS-EHV5-TR2011, RD-EHV5-TR2011, EHV5-TR-NS31 and EHV5-TR-NS26, as well as with isolates from the United States (SJ, Archey and Chantilly Lake) were from 98 to 99\%. Furthermore, Serbian EHV-5 isolates and strains were from 98 to $99 \%$ homogenous to both the Turkish isolate EHV5-TR-L2 and the South Korean strain KREHV5/71 that clustered together separately from all the above mentioned EHV-5 isolates and strains. 


\section{Discussion}

The standard technique for the laboratory diagnosis of equine herpesviral infections is the method of virus isolation followed by their confirmation using conventional or molecular methods. The RK-13 is a sensitive cell line for the propagation of EHV-1, EHV-2, and EHV-5 (Williams et al. 2007; Diallo et al. 2008; OIE 2008; Ataseven et al. 2010). In order to detect the presence of equine herpesviruses in organ samples of horses from Serbia, virus isolation was performed in the RK-13 cell line and the cytopathic effects were observed for EHV-1 and EHV-5 at the first and third passage, respectively. Wang et al. (2007) developed a nested multiplex PCR as a sensitive and specific technique for the simultaneous identification of equine alpha- and gammaherpesviruses in clinical samples from horses. In our study, we used this multiplex PCR method and concluded that it was more sensitive than virus isolation in cell culture for the detection of EHV-1, EHV-2, and EHV-5. Interestingly, one sample was PCR negative but showed CPE and was later confirmed as EHV-1. The diagnostic value of PCR is sometimes compromised by the presence of inhibitors; furthermore, the extraction of nucleic acids from biological samples may result in losses of the target DNA, both leading to false-negative results. For these reasons, the mentioned issue may be identified and bypassed using internal controls in multiplex PCR assays as described by Markoulatos et al. (2000), which was not carried out in our assay. In our examination, multiplex nested PCR has proved useful in detecting mixed infections with all three viruses in different organ samples.

The EHV-2 was present only as a mixed infection with EHV-1 or both EHV-1 and EHV-5 in the samples from a single horse, whilst these samples were positive only for EHV-1 on the cell culture. Differently from our results, Banbura et al. (2006) documented that the samples positive for both EHV-1 and EHV-2 using nested PCR were only EHV-2 positive after virus isolation in cell culture. Edington et al. (1994) did not isolate EHV-1 from neural tissue, contrarily to our findings. The authors have isolated EHV-2 from over $75 \%$ of the examined lymph nodes draining the respiratory tract. In our investigation, the presence of EHV-2 was detected only as a mixed infection by multiplex PCR in samples of the spinal cord, submandibular lymph nodes, and spleen from a single horse. Pusterla et al. (2010) determined the higher prevalence of latent EHV-1 in trigeminal ganglia $(12.4 \%)$ than submandibular lymph nodes (3.3\%). The highest prevalence of EHV-1 recorded in our study was documented in the lymphoid tissue (spleen and submandibular lymph nodes). In this examination, EHV-5 was confirmed by multiplex nested PCR in samples of the submandibular lymph nodes and spleen $(10.6 \%$ of the examined samples), whilst virus isolation was successful in $6.1 \%$ samples. Differently from our results, in the organs of healthy foals and adult horses including samples of spleen and lymph nodes, EHV-2 was more prevalent than EHV-5 which was not found alone in any of the samples (Torfason et al. 2008). Moreover, in comparison to this examination, many studies document the higher prevalence of EHV-2 compared to EHV-5 as well as difficulties in EHV-5 isolation (Nordengrahn et al. 2002; Bell et al. 2006; Williams et al. 2007). Significant variations within the glycoprotein B region found in different EHV-2 strains might explain its low detectability in the examined samples since we used gB gene specific primers in our study (Bell et al. 2006; Brault et al. 2011). The EHV-5 strains included in this study originated from horses of up to 2 years of age which is in agreement with the recorded age-dependent prevalence of EHV-5 by other authors (Nordengrahn et al. 2002; Diallo et al. 2008). The results of the phylogenetic analysis of partial $\mathrm{gB}$ gene sequences of two Serbian EHV-1 isolates showed that they were closely related to EHV-1 strains from Turkey, the United Kingdom, the United States, and Japan. The results of Turan et al. (2012) indicated that most of the Turkish EHV-1 strains clustered together, whilst one strain was slightly removed from the group clustering with European EHV-1 strains. Ataseven et 
al. (2016) determined that EHV-1 isolates in Turkey associated with abortion were closely related to the European EHV-1 strains. The Serbian EHV-2 strain branched together with Turkish EHV-2 isolates and their homogeneity was from 96 to $98 \%$. Ataseven et al. (2010) revealed a sequence divergence between Turkish isolates and European strains, i.e. that none of the studied Turkish EHV-2 isolates were $100 \%$ identical to strains from Europe. Correspondingly, the homogeneities found between the Serbian EHV-2 strain and some European strains were from 96 to $89 \%$. Moreover, the EHV-2 strain in our study shared only $78 \%$ similarity to the Icelandic EHV-2 isolate (Swe-2). Equine herpesvirus 5 isolates from Turkey were quite divergent from European isolates and they were located on a different branch in the phylogenetic tree (Ataseven et al. 2010). The Turkish isolates that clustered with Serbian EHV-5 strains and isolates originated from the same region in Turkey. The comparison of the gB gene of Turkish EHV-5 isolates showed marked heterogeneity as these isolates shared $77.3-90.2 \%$ nucleotide sequence identities with each other. On the other hand, Serbian EHV-5 isolates included in our examination were 96$100 \%$ homogenous. Similarly, the Ethiopian EHV-5 strains showed an overall nucleotide sequence identity of $95.1-100 \%$ amongst each other and $95.1-99.5 \%$ with reference strains from GenBank (Negussie et al. 2017). The described genetic heterogeneity in equine gammaherpesviruses corresponds with the results of studies conducted elsewhere, although the genomic variation in the gB gene of EHV-5 occurs to a lesser extent than EHV-2 (Bell et al. 2006; Brault et al. 2011).

The viral strains analyzed in our examination were obtained from animals distributed in different parts of Serbia suggesting that both equine alpha- and gammaherpesviruses are widely distributed in the horse population in Serbia. All samples were obtained from the organs of clinically healthy animals designated as the sites of EHV latency, indicating the presence of latent herpesvirus infections. The similarity of Serbian EHV-1, EHV-2, and EHV-5 strains with Turkish strains of the corresponding viruses could be explained by the active trade of animals that occurs across Serbia between eastern countries on one side and Europe on the other side.

We could underline that virus isolation and multiplex PCR detection with consecutive molecular typing are very suitable methods for equine herpesvirus detection and characterization. Nevertheless, our results demonstrate that multiplex PCR is convenient for routine diagnostics of equine herpesviral infections given its reliability, the ability of detecting mixed infections as well as the possibility of examining numerous samples in a short period of time which is important in equine clinical practice. The results of this study represent the first report of molecular detection and characterization of EHV-1, EHV-2, and EHV-5 and also give insight on the distribution of EHV-1 in the horse population of Serbia. Additionally, this examination documents the first successful isolation of Serbian EHV-5 strains. More data and research are needed to further investigate the presence of equine herpesviruses in a variety of samples to define their prevalence in both healthy and diseased horses in the Republic of Serbia.

\section{Acknowledgements}

This study was realized within the Project Grant no. TR31008 financed by The Ministry of Education, Science and Technological Development of the Republic of Serbia.

\section{References}

Ataseven VS, Bilge-Dagalp S, Oguzoglu TC, Karapinar Z, Guzel M, Tan MT 2010: Detection and sequence analysis of equine gammaherpesviruses from horses with respiratory tract disease in Turkey. Transbound Emerg Dis 57: 271-276

Ataseven VS, Oguzoglu TC, Dincer E, Bilge Dagalp S 2016: Partial sequence of the gB gene of equid herpesvirus type 1 isolates associated with abortion in Turkey. Ankara Univ Vet Fak Derg 63: 277-281 
Banbura MW, Witkowski L, Chmielewska A, Tucholska A 2006: Mixed infections of equine herpes virus types 1 and 2 (EHV-1 and EHV-2). Med Weter 62: 1071-1072

Bell SA, Balasuriya UB, Gardner IA, Barry PA, Wilson WD, Ferraro GL, MacLachlan NJ 2006: Temporal detection of equine herpesvirus infections of a cohort of mares and their foals. Vet Microbiol 116: 249-257

Brault SA, Bird BH, Balasuriya UB, MacLachlan NJ 2011: Genetic heterogeneity and variation in viral load during equid herpesvirus-2 infection of foals. Vet Microbiol 147: 253-261

Davison AJ, Eberle R, Ehlers B, Hayward GS, McGeoch DJ, Minson AC, Pellett PE, Roizman B, Studdert MJ, Thiry E 2009: The order Herpesvirales. Arch Virol 154: 171-177

Diallo IS, Hewitson GR, de Jong A, Kelly MA, Wright DJ, Corney BG, Rodwell BJ 2008: Equine herpesvirus infections in yearlings in South-East Queensland. Arch Virol 153: 1643-1649

Edington N, Welch HM, Griffiths L 1994: The prevalence of latent equid herpesviruses in the tissues of 40 abattoir horses. Equine Vet J 26: 140-142

Markoulatos P, Mangana-Vougiouka O, Koptopoulos G, Nomikou K, Papadopoulos O 2000: Detection of sheep poxvirus in skin biopsy samples by a multiplex polymerase chain reaction. J Virol Methods 84: 161-167

Negussie H, Gizaw D, Tesfaw L, Li Y, Oguma K, Sentsui H, Tessema TS, Nauwynck HJ 2017: Detection of equine herpesvirus (EHV) $-1,-2,-4$ and -5 in Ethiopian equids with and without respiratory problems and genetic characterization of EHV-2 and EHV-5 strains. Transbound Emerg Dis doi:10.1111/tbed.12601

Nordengrahn A, Merza M, Ros C, Lindholmc A, Palfl V, Hannant D, Belak S 2002: Prevalence of equine herpesvirus types 2 and 5 in horse populations by using type-specific PCR assays. Vet Res 33: 251-259

OIE. Equine rhinopneumonitis (equine herpesvirus -1 and -4). OIE Web site. Available at: https://web.oie.int/eng/ normes/MMANUAL/2008/pdf/2.05.09_EQUINE_RHINO.pdf Last modified 2008. Accessed June 29, 2017

Pusterla N, Mapes S, Wilson WD 2010: Prevalence of equine herpesvirus type 1 in trigeminal ganglia and submandibular lymph nodes of equids examined postmortem. Vet Rec 167: 376-378

Torfason EG, Thorsteinsdottir L, Torsteinsdottir S, Svansson V 2008: Study of equid herpesviruses 2 and 5 in Iceland with a type-specific polymerase chain reaction. Res Vet Sci 85: 605-611

Turan N, Yildirim F, Altan E, Sennazli G, Gurel A, Diallo I, Yilmaz H 2012: Molecular and pathological investigations of EHV-1 and EHV-4 infections in horses in Turkey. Res Vet Sci 93: 1504-1507

Wang L, Raidal SL, Pizzirani A, Wilcox GE 2007: Detection of respiratory herpesviruses in foals and adult horses determined by nested multiplex PCR. Vet Microbiol 121: 18-28

Williams KJ, Maes R, Del Piero F, Lim A, Wise A, Bolin DC, Caswell J, Jackson C, Robinson NE, Derksen F, Scott MA, Uhal BD, Li X, Youssef SA, Bolin SR 2007: Equine multinodular pulmonary fibrosis: a newly recognized herpesvirus-associated fibrotic lung disease. Vet Pathol 44: 849-862 
Plate III

Radalj A. et al.: Detection and ... pp. 27-34
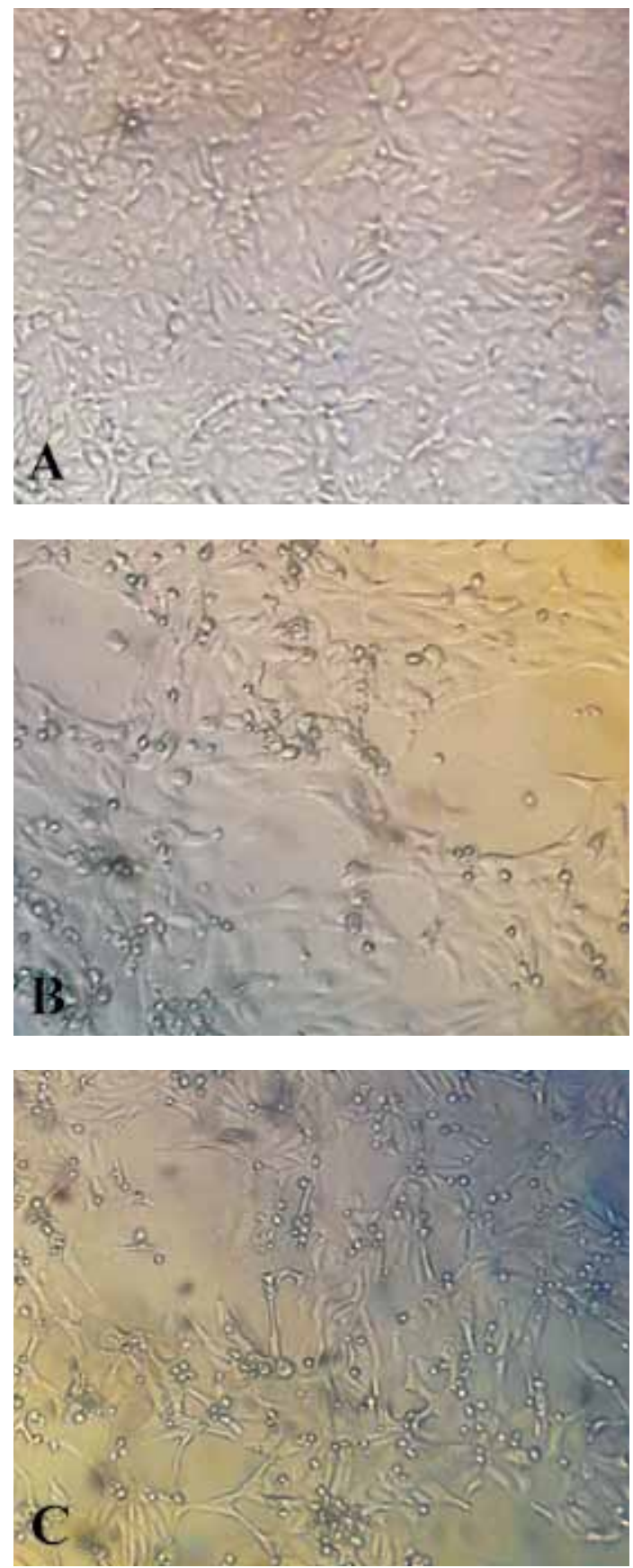

Fig. 1. The cytopathic effect (CPE) in the RK-13 cell line. A - Uninoculated cell monolayer (negative control). $\mathrm{B}-$ Equine herpesvirus $1 \mathrm{CPE} 72 \mathrm{~h}$ after the first inoculation. $\mathrm{C}-$ Equine herpesvirus $5 \mathrm{CPE}$ at day 5 of the third passage. 